\title{
LOS INTERCAMBIOS DE INFORMACIÓN ENTRE COMPETIDORES DESDE EL PUNTO DE VISTA DEL DERECHO DE LA COMPETENCIA Y SU CALIFICACIÓN COMO INFRACCIONES "POR OBJETO"
}

\author{
Autores $^{1}$ : Andrew Ward ${ }^{2}$ \\ Socio de Cuatrecasas Gonçalves Pereira, Madrid \\ Pablo Lavandeira Suárez $z^{3}$ \\ Asociado Principal de Cuatrecasas Gonçalves Pereira, Madrid
}

\begin{abstract}
Resumen
Los intercambios de información entre competidores pueden ser una infracción de la normativa de defensa de la competencia, si bien algunos intercambios

\footnotetext{
${ }^{1}$ Los autores quieren agradecer la contribución a este artículo de Cani Fernández, socia de Cuatrecasas Gonçalves Pereira y de Laura Pinilla Villalba, asociada de Cuatrecasas Gonçalves Pereira.

2 andrew.ward@cuatrecasas.com.

${ }^{3}$ pablo.lavandeira@cuatrecasas.com.
} 
también podrán ser pro-competitivos y generar eficiencias en el mercado. Para poder evaluar los intercambios de información se debe atender principalmente a la estructura del mercado afectado, a las características de la información intercambiada y al modo en que se producen los intercambios de información. Los intercambios de información son una de las infracciones más investigadas y sancionadas en los últimos años por parte de las autoridades españolas de defensa de la competencia. En sus resoluciones, las autoridades españolas suelen considerar que un intercambio de información entre competidores constituye una infracción de la normativa de defensa de la competencia "por objeto", aun cuando sea dudoso que los datos puedan ser estratégicos, por lo que no es necesario probar sus efectos restrictivos en el mercado. Muchos de estos casos han sido recurridos ante la jurisdicción contencioso-administrativa y sería deseable que en las sentencias que los resuelvan se aclaren estos aspectos.

Palabras clave: intercambio de información entre competidores; infracción "por objeto"; dato estratégico.

\title{
Information exchanges between competitors under competition law and their assessment as infringements "by object"
}

\begin{abstract}
Information exchanges between competitors can constitute an infringement of competition law, although some exchanges may be pro-competitive and generate efficiencies in the market. To evaluate information exchanges we should pay attention mainly to the structure of the affected market, the characteristics of the exchanged information and the way in which the exchanges took place. Information exchanges are one of the most investigated and sanctioned infringements by the Spanish competition authorities in recent years. In their resolutions, the Spanish competition authorities consider the information exchanges between competitors as an infringement of competition law "by object" even where the data concerned appear not to be strategic and, as a result, they do not consider necessary to demonstrate that they are capable of restricting competition. Many of these cases have been appealed before the Spanish courts and it is hoped that the Courts will clarify these issues.
\end{abstract}

Key words: information exchanges, infringement "by object"; strategic data. 
LOS INTERCAMBIOS DE INFORMACIÓN ENTRE COMPETIDORES DESDE EL PUNTO DE VISTA DEL DERECHO...

\section{INTRODUCCIÓN}

Los intercambios de información entre competidores se han convertido en los últimos años en una de las infracciones más habituales del Derecho de la Competencia español siendo cada vez más numerosas las resoluciones de la Comisión Nacional de los Mercados y la Competencia ("CNMC"4) que los sancionan.

De un total de 22 resoluciones sancionadoras adoptadas por la CNMC en aplicación del artículo 1 de la Ley 15/2007, de 3 de julio, de Defensa de la Competencia ("LDC") desde 2014 hasta el momento de escribir este artículo, en quince de ellas la CNMC ha sancionado, entre otras prácticas, intercambios de información entre empresas competidoras si bien solo en dos de las resoluciones se podría afirmar que la CNMC ha sancionado intercambios de información "puros", es decir, sin que el intercambio formase parte de una infracción compleja compuesta por varias prácticas anticompetitivas (los asuntos "Servicios comerciales AENA" y "Palés").

En otros casos, el intercambio de información entre competidores es la infracción principal sancionada como ha ocurrido en el asunto "Industrias Lácteas 2", donde la CNMC ha sancionado a nueve compañías y dos asociaciones que operan en el mercado de aprovisionamiento de leche cruda de vaca por haber principalmente intercambiado información a nivel nacional y regional sobre precios y volúmenes de compra con el objetivo de adoptar una estrategia conjunta para controlar el mercado de aprovisionamiento de leche cruda. En otro grupo de asuntos, el intercambio de información entre competidores es simplemente una rama más de una infracción más amplia y compleja que incluye otras conductas principales como acuerdos para la fijación del precio o para el reparto de mercado?

En sus resoluciones, las autoridades españolas de defensa de la competencia suelen considerar que un intercambio de información entre competidores cons-

\footnotetext{
${ }^{4}$ A lo largo de este artículo nos referiremos además de a la CNMC a la Comisión Nacional de la Competencia ("CNC") en vigor desde 2007 a 2013 y al Servicio de Defensa de la Competencia ("SDC") y al Tribunal de Defensa de la Competencia ("TDC”), el órgano de instrucción y el órgano de resolución, respectivamente, activos bajo la antigua Ley 16/1989, de 17 de julio, de Defensa de la Competencia.

${ }^{5}$ Resolución de la CNMC de 2 de enero de 2014 en el expediente S/0404/12, Servicios comerciales AENA y Resolución de 22 de septiembre de 2014 en el expediente S/0428/12, Palés. Debe destacarse que en el asunto "Servicios comerciales AENA", la CNMC, si bien solo investigó y sancionó a las empresas por un intercambio de información, concluyó que la infracción debía subsumirse en un cártel sancionado en otro expediente (S/0380/11 Coches de alquiler) pero no investigado en el expediente S/0404/12. Por su parte en "Palés", la CNMC además de investigar y sancionar a determinadas empresas solo por intercambios de información, también sancionó separadamente a otro grupo de empresas (algunas coincidentes) por un cártel en el mismo producto.

${ }^{6}$ Resolución de 26 de febrero de 2015 en el expediente S/0425/12, Industrias lácteas 2.

${ }^{7}$ Por ejemplo, en el asunto de la CNMC seguido contra varios operadores de productos petrolíferos (Resolución de 25 de febrero de 2015 en el expediente S/0474/13) donde cinco de estas empresas fueron sancionadas por acuerdos de precios, pactos de no agresión, así como diversos intercambios de información bilaterales.
} 
tituye una infracción de la normativa de defensa de la competencia "por objeto" por lo que no es necesario probar sus efectos restrictivos en el mercado. Muchos de estos casos han sido recurridos ante la jurisdicción contencioso-administrativa y sería deseable que en las sentencias que los resuelvan se aclaren estos aspectos.

Sin embargo, no todos los intercambios de información son "per se" una infracción de la normativa de defensa de la competencia. Al contrario, existen intercambios de información entre competidores que generan eficiencias y son por lo tanto pro-competitivos ${ }^{8}$. Saber distinguir cuando un intercambio de información entre competidores puede constituir una infracción o cuando es procompetitivo no es una tarea sencilla por lo que es necesario autoevaluar el intercambio de forma circunstanciada, atendiendo principalmente a (i) la estructura del mercado afectado; (ii) las características de la información intercambiada; y (iii) el modo en que se producen los intercambios de información.

La ausencia de regulación legal específica sobre los intercambios de información ha puesto en valor la práctica decisoria de las autoridades de competencia, de los tribunales y sobre todo de las Directrices sobre la aplicabilidad del artículo 101 del TFUE a los acuerdos de cooperación horizontal ("Directrices horizontales") ${ }^{9}$, que han desarrollado las pautas para su análisis.

En el siguiente artículo analizaremos la normativa básica aplicable a los intercambios de información entre competidores, veremos cómo se evalúan desde el punto de vista de la normativa de defensa de la competencia y cuál es la metodología y los criterios de análisis. También veremos algunos de los casos más importantes investigados por la Comisión Europea y por las autoridades españolas de defensa de la competencia y plantearemos algunas cuestiones de interés.

\section{NORMATIVA APLICABLE}

Los intercambios de información entre competidores no están regulados legalmente de manera específica por lo que su análisis se viene realizando bajo las normas que regulan el derecho de defensa de la competencia: la LDC $^{10}$ y el Tratado de Funcionamiento de la Unión Europea ("TFUE")11.

${ }^{8}$ Jones, A. y Sufrin, B., EU Competition Law, $5^{\mathrm{a}}$ ed., Oxford University Press, Oxford, 2014, p. 699.

${ }^{9}$ Directrices de la Comisión Europea sobre la aplicabilidad del artículo 101 del TFUE a los acuerdos de cooperación horizontal (2011/C 11/01), párrafos 55 a 110.

${ }^{10}$ Así como su Reglamento de desarrollo, el Real Decreto 261/2008, de 22 de febrero, por el que se aprueba el Reglamento de Defensa de la Competencia.

${ }^{11}$ La aplicación de las provisiones del TFUE dependerá de si el acuerdo analizado afecta o no a los intercambios dentro del mercado común. Es habitual que la CNMC suela invocar la aplicación del artículo 101 del TFUE en los expedientes que normalmente abarcan la totalidad o gran parte del territorio nacional. 


\subsection{Artículos 1 de la LDC y 101 del TFUE}

El intercambio de información entre competidores se analiza bajo el artículo 1.1 de la LDC por el que: "Se prohíbe todo acuerdo, decisión o recomendación colectiva, o práctica concertada o conscientemente paralela, que tenga por objeto, produzca o pueda producir el efecto de impedir, restringir o falsear la competencia en todo o parte del mercado nacional", y bajo el artículo 101.1 del TFUE que de manera casi idéntica establece que: "serán incompatibles con el mercado interior y quedarán prohibidos todos los acuerdos entre empresas, las decisiones de asociaciones de empresas y las prácticas concertadas que puedan afectar al comercio entre los Estados miembros y que tengan por objeto o efecto impedir, restringir o falsear el juego de la competencia dentro del mercado interior"12.

Como excepción a la prohibición general ${ }^{13}$ el artículo 1.3 de la LDC y el artículo 101.3 del TFUE prevén exceptuar aquellos acuerdos cuyo resultado contribuya a mejorar la producción o la comercialización y distribución de bienes y servicios o a promover el progreso técnico o económico, siempre que dichas mejoras (i) puedan ser compartidas equitativamente por los consumidores, (ii) no se creen restricciones competitivas que no sean imprescindibles para lograr las mejoras y (iii) que no se elimine la competencia de una parte sustancial del mercado afectado ${ }^{14}$.

Ni el artículo 1.1 de la LDC ni el artículo 101.1 del TFUE hacen referencia de forma expresa a los intercambios de información entre la lista no exhaustiva de prácticas anticompetitivas que incluyen ${ }^{15}$, encontrándose las normas aplicables a

${ }^{12}$ Como puede observarse, la principal diferencia entre el artículo 1.1 de la LDC y el artículo 101.1 del TFUE, aparte de su ámbito geográfico, es que el primero incluye la figura de la práctica conscientemente paralela y el segundo no.

${ }^{13}$ Debe destacarse además que, según el artículo 1.2 de la LDC y 101.2 del TFUE, los acuerdos prohibidos serán nulos de pleno derecho.

${ }^{14}$ Según el artículo 1.3. "La prohibición del apartado 1 no se aplicará a los acuerdos, decisiones, recomendaciones y prácticas que contribuyan a mejorar la producción o la comercialización y distribución de bienes y servicios o a promover el progreso técnico o económico, sin que sea necesaria decisión previa alguna a tal efecto, siempre que: a) Permitan a los consumidores o usuarios participar de forma equitativa de sus ventajas. b) No impongan a las empresas interesadas restricciones que no sean indispensables para la consecución de aquellos objetivos, y c) No consientan a las empresas partícipes la posibilidad de eliminar la competencia respecto de una parte sustancial de los productos o servicios contemplados". El artículo 101.3 del TFUE es materialmente idéntico.

${ }^{15}$ El artículo 1.1 de la LDC enumera las siguientes conductas: "a) La fijación, de forma directa o indirecta, de precios o de otras condiciones comerciales o de servicio. b) La limitación o el control de la producción, la distribución, el desarrollo técnico o las inversiones. c) El reparto del mercado o de las fuentes de aprovisionamiento. d) La aplicación, en las relaciones comerciales o de servicio, de condiciones desiguales para prestaciones equivalentes que coloquen a unos competidores en situación desventajosa frente a otros. e) La subordinación de la celebración de contratos a la aceptación de prestaciones suplementarias que, por su naturaleza o con arreglo a los usos de comercio, no guarden relación con el objeto de tales contratos”. El artículo 101.1 del TFUE también es materialmente idéntico en este aspecto. Por otro lado, tampoco se menciona a los intercambios de información en la clasificación que contiene la LDC sobre la gravedad de las infracciones (artículo 61 de la LDC que clasifica las infracciones como leves, graves y muy graves). Tampoco la definición de cártel incluida en la Disposición Adicional Cuarta, punto dos, de la LDC hace referencia al intercambio de 
los intercambios de información en la práctica decisoria de las autoridades españolas de defensa de la competencia y de la Comisión Europea ${ }^{16}$, en la jurisprudencia de los tribunales nacionales y de la Unión Europea ${ }^{17}$ y en las Directrices horizontales, que recogen de forma detallada los principios generales de la evaluación de los intercambios de información entre competidores en sus párrafos 55 a 110 y que desarrollamos en los siguientes apartados.

Por otro lado debe destacarse también que, de acuerdo con el párrafo 12 de las Directrices horizontales, algunos acuerdos verticales ${ }^{18}$ entre competidores (como por ejemplo los acuerdos de distribución) también podrían valorarse a la luz de los principios recogidos en las Directrices horizontales. Sin embargo, en la práctica, las autoridades de competencia se han centrado fundamentalmente en el análisis de los intercambios de información entre competidores de tipo horizontal y no de tipo vertical, si bien cabe destacar a este respecto la reciente Resolución de 18 de junio de 2015 en el asunto "Fabricantes de papel y cartón ondulado"19, en la cual la CNMC ha destacado la fuerte vinculación existente entre los dos mercados investigados (la fabricación del papel -mercado aguas arriba- y la fabricación del cartón ondulado - mercado aguas abajo- en donde el principal insumo es precisamente el papel) llegando a asegurar, por lo que respecta a la infracción relativa al intercambio de información entre empresas papeleras, que dicho intercambio no sólo se realizaba exclusivamente entre ellas sino también con empresas aguas abajo que tenían como materia prima fundamental el papel y que trataban de manipular los precios de esta materia prima aguas arriba con el fin de fijar el precio del cartón ondulado más interesante para ellos ${ }^{20}$.

información: "A efectos de lo dispuesto en esta Ley se entiende por cártel todo acuerdo secreto entre dos o más competidores cuyo objeto sea la fijación de precios, de cuotas de producción o de venta, el reparto de mercados, incluidas las pujas fraudulentas, o la restricción de las importaciones o las exportaciones".

${ }^{16}$ A nivel nacional, ver, entre otras, Resolución de la CNC de 7 de febrero de 2011 en el expediente S/0155/09, STANPA; Resolución de la CNC de 24 de junio de 2011 en el expediente S/0185/09, Bombas de fluido. A nivel comunitario, ver, entre otras, la Decisión de la Comisión Europea de 17 de diciembre de 1992 en el asunto UK Agricultural Tractor Registration Exchange (IV/31.370 y 31.446); Decisión de la Comisión Europea de 13 de julio de 1994 en el asunto Cartonboard (IV/C/33.833); y Decisión de la Comisión Europea de 26 de noviembre de 1997 en Wirtschaftsvereinigung Stahl (IV/36.069).

${ }^{17}$ Ver, entre otras, Sentencia de 23 de noviembre de 2006, del Tribunal de Justicia de las Comunidades Europeas ("TJCE") en el asunto C-238/05 Asnef-Equifax/Ausbanc o Sentencia de 4 de junio de 2009 del Tribunal de Justicia de la Unión Europea ("TJUE") en el asunto C-8/08, T-Mobile Netherlands and others.

${ }^{18}$ Los acuerdos verticales son aquellos acuerdos celebrados entre empresas situadas en niveles distintos de las cadenas de producción o distribución.

${ }^{19}$ Resolución de 18 de junio de 2015 en el expediente S/0469/12, Fabricantes de papel y cartón ondulado por la cual la CNMC ha sancionado con un total de 57,7 millones de euros a varias empresas del sector de la fabricación de papel (por intercambios de información en relación con los precios del papel) y del cartón ondulado (intercambios de información para coordinar subidas de precios y repartos de clientes).

${ }^{20}$ Ver a estos efectos la página 110 de la Resolución. 


\subsection{Clasificación de los intercambios de información entre competidores}

Los acuerdos de intercambio de información entre competidores se han clasificado habitualmente en las tres categorías siguientes: (i) como parte de un acuerdo más amplio de fijación de precios o reparto de mercados en el que el intercambio de información opera como un factor facilitador ${ }^{21}$; (ii) en el contexto de acuerdos de cooperación horizontal ${ }^{22}$; o (iii) como intercambios de información aislados (stand-alone o puros) $)^{23}$.

Por otro lado, las Directrices horizontales consideran que un intercambio de información entre competidores también podrá constituir un cártel. Así en su párrafo 59 indica que: "la comunicación de información entre competidores puede constituir un acuerdo, una práctica concertada o una decisión de una asociación de empresas con objeto de fijar, en particular, precios o cantidades. Por norma general, esos tipos de intercambio de información se considerarán cárteles y, como tales, serán multados" 24 .

La consideración de un intercambio de información entre competidores como un cártel puede tener efectos muy importantes por lo que se refiere a la posible aplicación del programa de clemencia, cuyo ámbito material está limitado a casos de cártel. En la práctica las autoridades españolas de defensa de la competencia han considerado que un intercambio de información constituye un cártel en, por ejemplo, el asunto "Bombas de Fluidos"25, en donde la CNC indicó que los intercambios de información entre varias empresas del sector de las bombas de fluidos relativos a incrementos de precios futuros y sus fechas de entrada en vigor, previsiones de producción y demanda, políticas salariales y cifras de facturación de bombas de fluidos podían calificarse de cártel junto con el resto de conductas sancionadas.

Los acuerdos de intercambio de información entre competidores pueden además revestir diferentes formas. De acuerdo con el párrafo 55 de las Directrices

\footnotetext{
${ }^{21}$ Párrafo 59 de las Directrices horizontales que se refiere en concreto a aquellos intercambios de información que pueden facilitar la implementación de un cártel cuando permiten a las compañías controlar si los participantes cumplen o no con los acuerdos pactados. Este tipo de intercambio se evaluará como parte del cártel.

${ }^{22}$ Párrafo 56 de las Directrices horizontales pone como ejemplo un acuerdo de producción donde las partes del mismo comparten cierta información sobre costes. La evaluación de este último tipo de intercambio de información debería llevarse a cabo en el contexto de una evaluación del respectivo acuerdo de cooperación horizontal.

${ }^{23}$ Párrafo 55 de las Directrices horizontales acertadamente los denomina como intercambios "cuya función económica principal es el intercambio de la información propiamente dicho".

${ }^{24}$ En el párrafo 74 de las Directrices horizontales se vuelve a hacer mención a ello al indicar que "los intercambios privados entre competidores relativos a sus intenciones en materia de futuros precios o cantidades se considerarán normalmente cárteles y serán multados como tales puesto que, por lo general, tienen por objeto fijar precios o cantidades".

${ }^{25}$ Resolución de 24 de junio de 2011 en el expediente S/0185/09, Bombas de fluidos.
} 
horizontales, los intercambios pueden realizarse de tres maneras distintas: (i) los competidores pueden compartir datos de forma directa entre ellos; (ii) los competidores pueden compartir datos de forma indirecta a través de un organismo común (por ejemplo, una asociación empresarial); o (iii) los competidores pueden compartir datos a través de un tercero, como por ejemplo una organización de investigación de mercado o proveedores de las empresas o de los minoristas.

Finalmente debe destacarse que un intercambio de información entre competidores también puede ser una infracción aun cuando el infractor ha actuado unilateralmente. Por ejemplo, si solo una empresa revela información que constituye secreto de negocio a varios competidores a través de correos postales o llamadas telefónicas, se puede producir igualmente una reducción de la incertidumbre estratégica en el mercado y aumentar el riesgo de disminución de la competencia y de llegar a un comportamiento colusorio ${ }^{26}$.

\subsection{Método de evaluación general}

Para que un intercambio de información entre competidores pueda analizarse bajo los artículos 1 de la LDC y 101 del TFUE debe, como punto de partida, ser o formar parte de un acuerdo, decisión o recomendación colectiva, o práctica concertada (o conscientemente paralela según el artículo 1.1 de la LDC).

Los intercambios de información entre competidores son considerados una forma de práctica concertada tal y como se indica en los apartados 60 y 61 de las Directrices horizontales. En concreto, conforme a la jurisprudencia comunitaria, el concepto de práctica concertada "se refiere a una forma de coordinación entre las empresas mediante la cual estas, sin haber llegado nunca la realización de un acuerdo propiamente dicho sustituyen conscientemente los riesgos de la competencia por una cooperación practica entre ellas"27. En este sentido, lo que se prohíbe no es que las empresas se adapten a la conducta visible o prevista de sus competidores sino las tomas de contacto directas o indirectas entre competidores cuyo objeto o efecto sea influir en la conducta de un competidor o desvelar a dicho competidor una conducta que se haya decidido o se tenga la intención de adoptar. En esas circunstancias, el intercambio de información entre competidores puede constituir por lo tanto una práctica concertada si reduce la incertidumbre estratégica en el mercado facilitando la colusión.

Con carácter previo debe destacarse en todo caso que un intercambio de información entre competidores no constituye "per se" una infracción del Derecho de la Competencia. Al contrario, son numerosos los ejemplos de intercambios de

${ }^{26}$ Ver párrafos 62 y 63 de las Directrices horizontales donde se describen diferentes situaciones a este respecto.

${ }^{27}$ Ver a estos efectos, el asunto C-8/08, T-Mobile Netherlands, considerando 26 o los asuntos acumulados C-89/85 y otros, Wood Pulp, considerando 63. 
información entre competidores beneficiosos, tal y como recoge el párrafo 57 de las Directrices horizontales:

"El intercambio de información es una característica común a muchos mercados competitivos que puede generar diversos tipos de eficiencia. Puede solucionar problemas de asimetrías de la información, incrementando así la eficiencia de los mercados. Además, las empresas mejoran a menudo su eficiencia interna a partir de una comparación con las mejores prácticas de las demás. El intercambio de información también puede ayudar a las empresas a ahorrar costes reduciendo sus existencias, haciendo posible una entrega más rápida de los productos perecederos a los clientes o resolviendo la inestabilidad de la demanda. Asimismo, los intercambios de información pueden beneficiar directamente a los consumidores reduciendo sus costes de búsqueda y mejorando sus posibilidades de elección”.

En cuanto a los principales problemas de competencia que se derivan de un intercambio de información entre competidores, estos se encuentran detallados en las Directrices horizontales (párrafos 65 a 71) y se pueden resumir en dos tipos: el intercambio de información entre competidores puede dar lugar a un resultado colusorio o puede generar una exclusión contraria a la competencia.

En el primer caso, el intercambio de información entre competidores, al aumentar artificialmente la transparencia en el mercado, puede facilitar la coordinación entre las empresas y dar lugar a efectos restrictivos de la competencia. En el segundo caso, el intercambio de información entre competidores puede dar lugar a una exclusión anticompetitiva cuando sitúa a los competidores que no han participado en el acuerdo en una situación de desventaja competitiva significativa con respecto a las empresas que sí han participado en dicho acuerdo.

La evaluación con arreglo a los artículos 1 de la LDC y 101 del TFUE tiene dos fases ${ }^{28}$. En la primera fase se debe evaluar, de conformidad con el apartado 1 de ambos artículos, si el intercambio de información entre competidores tiene un objeto contrario a la competencia o unos efectos reales o potenciales restrictivos de la competencia. En la segunda fase, y solo en el caso de que se concluya que el intercambio es en efecto restrictivo de la competencia, se determina si se cumplen los criterios que justifican una exención de conformidad con el apartado 3 de ambos artículos, al entenderse que los efectos positivos del intercambio de información compensan las restricciones de la competencia del mismo.

\footnotetext{
${ }^{28}$ El método de evaluación para los intercambios de información entre competidores es el método general de evaluación aplicable a todos los acuerdos entre competidores según las Directrices horizontales, si bien los intercambios de información entre competidores son también objeto de desarrollo específico en los apartados 55 a 110 de las Directrices horizontales.
} 
Solo podrán ser considerados como una infracción de la normativa de competencia aquellos intercambios de información entre competidores que tengan por objeto o efecto restringir la competencia. Sin embargo, la práctica habitual de la CNMC y de sus antecesores es la de considerar a los intercambios de información como una restricción "por objeto" (e incluso como un cártel en sí mismo ${ }^{29}$ ) de manera automática sin que sea por lo tanto necesario probar sus efectos.

\subsection{Intercambio de información entre competidores "por objeto"}

En el apartado 24 de las Directrices horizontales se indica que: "Se entiende por restricciones de la competencia por el objeto aquéllas que por su propia naturaleza poseen el potencial de restringir la competencia a tenor del artículo 101, apartado 1".

En el apartado 25 también se indica que "[...] para apreciar el carácter contrario a la competencia de un acuerdo, procede examinar particularmente su contenido, la finalidad objetiva que pretende alcanzar, así como el contexto económico y jurídico en que se inscribe. Además, si bien la intención de las partes no constituye un elemento necesario para determinar el carácter contrario a la competencia de un acuerdo, nada impide a la Comisión tenerla en cuenta en su análisis". En este sentido, debe destacarse que "por objeto" las Directrices horizontales se están realmente refiriendo a la finalidad objetiva de un acuerdo o práctica concertada lo que no excluye sin embargo que se tenga también en cuenta en el análisis la intención o elemento subjetivo de las partes a la hora de adoptar un intercambio de información entre competidores.

Más específicamente en los párrafos 72 a 74 de las Directrices horizontales se establece que cualquier intercambio de información entre competidores cuyo objetivo sea la restricción de la competencia se considerará restrictivo de la competencia "por objeto". En este sentido, para evaluar si un intercambio constituye una infracción "por objeto" deberá prestarse especial atención al contexto jurídico y económico del intercambio ${ }^{30}$.

El párrafo 73 precisa que es particularmente probable que el intercambio de información sobre las intenciones individuales de las empresas en cuanto a su conducta futura relativa a precios o cantidades desemboque en una restricción de la competencia por el objeto. Además, los intercambios privados entre competidores relativos a sus intenciones en materia de futuros precios o cantidades se considerarán normalmente cárteles y serán multados como tales puesto que, por lo general, tienen por objeto fijar precios o cantidades ${ }^{31}$.

\footnotetext{
${ }^{29}$ Resolución de 24 de junio de 2011 en el expediente S/185/09, Bombas de fluidos.

${ }^{30}$ Ver a estos efectos, los asuntos acumulados C-501/06 P y otros, GlaxoSmith Kline, considerando 58 y asunto C-209/07 BIDS, considerandos 15 y siguientes.

${ }^{31}$ Párrafo 74 de las Directrices horizontales.
} 
LOS INTERCAMBIOS DE INFORMACIÓN ENTRE COMPETIDORES DESDE EL PUNTO DE VISTA DEL DERECHO...

En el asunto "T-Mobile", 32 el TJUE se pronunció sobre en qué medida un intercambio de información entre competidores puede ser considerado una restricción de la competencia "por objeto". En concreto, según el TJUE:

"ha de considerarse que tiene un objetivo contrario a la competencia un intercambio de información que puede eliminar la incertidumbre que sigue existiendo entre las partes en lo relativo a la fecha, el alcance y las modalidades de la adaptación que la empresa interesada pone en práctica, incluido, como en el litigio principal, cuando la adaptación se refiere a la reducción de la retribución estándar de los distribuidores" (...) "una práctica concertada tiene un objeto contrario a la competencia en el sentido del artículo [101] CE, apartado 1, cuando por su contenido y su objetivo, y teniendo en cuenta el contexto jurídico y económico en el que se inscribe, es apta para impedir, restringir o falsear el juego de la competencia dentro del mercado común de manera concreta. A estos efectos, no es necesario que se impida, restrinja o falsee efectivamente el juego de la competencia ni que exista una relación directa entre la práctica concertada y los precios al consumo final. El intercambio de información entre competidores tendrá un objetivo contrario a la competencia cuando sea apto para suprimir la incertidumbre sobre el comportamiento en el mercado previsto por las empresas partícipes" (énfasis añadido).

Sin embargo, resulta cuestionable que un intercambio de información entre competidores que no se refiera expresamente a precios y conductas futuras pueda constituir de manera automática un acuerdo restrictivo de la competencia por objeto "por su propia naturaleza" o por ser "apto para suprimir la incertidumbre" (como sí lo serían los acuerdos de fijación de precios, limitación de la producción y reparto de mercado).

En este sentido, resulta muy relevante la sentencia de la Audiencia Nacional de 1 de diciembre de 2009 por la que se estima parcialmente un recurso contra la Resolución de la CNC de 18 de octubre de 2007 en el asunto llamado "Cajas Vascas", donde se señala:

“..., en relación con los demás acuerdos que se incluyen en la narración de hechos probados de la Resolución impugnada, de coordinación de actuaciones frente a terceros competidores, intercambio de información, coordinación y fijación de posturas comunes en sociedades participadas, y coordinación de actuaciones en relación con nuevos productos o sectores

\footnotetext{
${ }^{32}$ Sentencia de 4 de junio de 2009 del TJUE en el asunto C-8/08, T-Mobile Netherlands and others. Véase también las conclusiones de la Abogada General Kokott en este asunto y, en especial, sus consideraciones sobre las restricciones "por objeto" en los párrafos 43, 47, 70 y 71 del escrito de conclusiones.
} 
de actividad (acuerdos 3, 4, 5 y 6 de los enumerados en el fundamento jurídico $\mathrm{n}^{\circ} 5$ ), no puede presumirse que tengan por objeto, por su naturaleza, infringir la competencia, de acuerdo con las criterios jurisprudenciales del TJCE [Tribunal de Justicia de las Comunidades Europeas, actualmente denominado Tribunal de Justicia de la Unión Europea] y Directrices de la Comisión sobre la aplicabilidad del artículo 81 del Tratado CE [actualmente denominado artículo 101 TFUE] ( RCL 1999, 1205 ter) a los acuerdos de cooperación horizontal (DOCE 2001/C - 3/02 ) y las Directrices relativas a la aplicación del apartado 3 del artículo 81 del Tratado (DOCE 2004/C - 101/08 ), previamente citadas, que como se ha visto extienden la presunción de ser restrictivos de la competencia por su objeto únicamente a los acuerdos de fijación de precios, limitación de la producción y reparto del mercado.

Tratándose de otra clase de acuerdos, se hace el necesario comprobar si los mismos producen efectos contrarios a la competencia, sin que esta apreciación pueda realizarse de forma desligada de las circunstancias concurrentes en el caso, tales como el contexto económico, estructura y condiciones de funcionamiento del mercado pertinente, naturaleza de los bienes o servicios afectados, y otras.

La apreciación de los efectos anticompetitivos de un acuerdo no puede realizarse en abstracto, sino que exige tomar en consideración las condiciones y circunstancias en que se producen las prácticas, Así en el caso citado de la cuestión prejudicial planteada por el TS, el TJCE señaló que para apreciar los efectos anticompetitivos de los acuerdos contemplando en aquella ocasión, debía tomarse en consideración el marco concreto en el que se producen los acuerdos, y en particular, el contexto económico y jurídico en el que operan las empresas, la naturaleza de los bienes y servicios contemplados, así como la estructura y condiciones reales de funcionamiento de los mercados pertinentes (apartado 49 de la citada STJCE de 25 de noviembre de 2006).

Sin embargo, en el presente caso, el expediente no muestra ningún examen de esta naturaleza, ni existe ningún dato ni elemento que permitan el conocimiento del alcance de la ejecución de los acuerdos y sus consecuencias sobre la competencia, o al menos, un estudio sobre los efectos potenciales que los repetidos acuerdos hubieran podido producir sobre la competencia en el mercado afectado. Así las cosas, sin ninguna acreditación ni prueba, siquiera indiciaria, sobre los efectos restrictivos de la competencia, reales o potenciales, de los acuerdos que citamos, no es posible presumir que se 
trate de acuerdos prohibidos por el artículo 1 LDC (RCL 1989, 1591) por razón de sus efectos restrictivos de la competencia." (Subrayados propios).

Pese a esta jurisprudencia, las resoluciones de la CNMC y de sus antecesores en la materia suelen considerar de forma habitual que los intercambios de información entre competidores son infracciones "por objeto" sin que sea necesario analizar los efectos en el mercado ${ }^{33}$.

Más recientemente, el TJUE ha adoptado una sentencia el 11 de septiembre de 2014 en el asunto C-67/13 P, "CB/Comisión”34 de gran relevancia, pese a no referirse a un caso de intercambio de información entre competidores, a la hora de analizar el concepto de restricción de la competencia "por objeto". De acuerdo con la sentencia, este concepto debe siempre interpretarse de manera restrictiva indicando que el hecho de que un acuerdo tenga el potencial de restringir la competencia no es suficiente para poder calificarlo como un acuerdo restrictivo "por objeto". De acuerdo con el párrafo 58 de la sentencia:

"so pena de dispensar a la Comisión de la obligación de probar los efectos concretos en el mercado de acuerdos de los que no se ha demostrado en absoluto que sean nocivos por su propia naturaleza para el buen funcionamiento del juego normal de la competencia, el concepto de restricción de la competencia «por el objeto» sólo puede aplicarse a ciertos tipos de coordinación entre empresas que revelen un grado de nocividad para la competencia suficiente para que se pueda considerar innecesario el examen de sus efectos".

La sentencia indica a estos efectos en el párrafo 53 que para apreciar si un acuerdo tiene un "grado de nocividad suficiente" deben tenerse en cuenta una serie de factores, tales como el contenido de sus disposiciones, los objetivos que

\footnotetext{
${ }^{33}$ Ver a estos efectos: Resolución de la CNC de 7 de febrero de 2011 en el expediente S/0155/09, STANPA (Fundamento de Derecho Quinto: "Infracción por objeto de las conductas de STANPA"); Resolución de 19 de enero de 2012 en el expediente S/0280/10, Suzuki-Honda (Fundamento de Derecho Quinto: "Calificación jurídica del Consejo"); Resolución de la CNMC de 2 de enero de 2014 en el expediente S/0404/12, Servicios comerciales AENA (no se especifica en la Resolución que la conducta de intercambio de información sancionada constituyese una infracción "por objeto" si bien se deduce de su lectura que esa es la interpretación del Consejo quien además considera en su "Resuelvo Primero" que la conducta de intercambio de información sensible sancionada "debió subsumirse en el Expediente Sancionador S/0380/11 Coches de alquiler, por cuanto la denuncia de las conductas, las conductas y las infracciones, en ambos expedientes sancionadores, gozan de unidad de acto: creación de un cártel con la finalidad de fijar los precios en el mercado de los coches de alquiler sin conductor y el establecimiento de determinadas condiciones, así como el intercambio de información comercialmente sensible entre las empresas que lo conforman"); Resolución de 2 de septiembre de 2014 en el expediente S/0428/12, Palés (Apartado 4.2.2) o Resolución de 26 de febrero de 2015 en el expediente S/0425/12, Industrias lácteas 2 (Apartado 4.1.1).

${ }^{34}$ Sentencia del TJUE de 11 de septiembre de 2014 (conocida como sentencia Cartes Bancaires).
} 
pretende alcanzar y el contexto económico y jurídico en el que se inscribe. En relación con el contexto, es preciso considerar también la naturaleza de los bienes y servicios afectados y las condiciones reales del funcionamiento y de la estructura de los mercados pertinentes.

Por lo tanto, de acuerdo con esta sentencia, es necesario justificar que una determinada restricción de la competencia tiene un grado de nocividad suficiente para ser considerada como restricción "por objeto" y para ello deben tenerse en cuenta los factores enumerados anteriormente.

Ante este tipo de acuerdos que no se consideran anticompetitivos "per se" es necesario comprobar si producen efectos contrarios a la competencia y no sólo en abstracto sino tomando en consideración el marco concreto en el que se producen los acuerdos, y en particular, el contexto económico y jurídico en el que operan las empresas, la naturaleza de los bienes y servicios contemplados, así como la estructura y condiciones reales de funcionamiento de los mercados pertinentes.

En la resolución más reciente publicada en la página web de la CNMC en el momento de escribir este artículo, la Resolución de 18 de junio de 2015 en el asunto "Fabricantes de papel y cartón ondulado", la CNMC ha considerado, en lo que podría interpretarse como un posible nuevo enfoque en la materia, que el intercambio de información sobre el precio de fabricación de papel para el cartón ondulado no podía considerarse como una infracción "por objeto" al no tratarse de precios futuros sino simplemente pasados.

\subsection{Intercambio de información entre competidores: posibles efectos restric- tivos}

El análisis de los efectos reales o potenciales de un intercambio de información entre competidores sobre la competencia debe realizarse de manera individualizada caso por caso y sobre la base de dos aspectos fundamentales: las características del mercado en el que se produce el intercambio de información y las características de la información intercambiada.

\subsubsection{Características del mercado}

De acuerdo con el párrafo 77 de las Directrices horizontales, es más probable que se produzca un resultado colusorio en mercados "suficientemente transparentes, concentrados, sencillos, estables y simétricos" ${ }^{35}$.

En efecto, un intercambio de información entre competidores puede aumentar la transparencia en un mercado limitando las incertidumbres sobre los datos

\footnotetext{
${ }^{35}$ Recuerda, M. y otros, Problemas prácticos y actualidad del derecho de la competencia Anuario 2014, $1^{\mathrm{a}}$ ed., Civitas Thomson Reuters, Pamplona, 2014, pp. 26-28.
} 
estratégicos más relevantes como los precios, la producción o la demanda. Cuanto más bajo sea el nivel de transparencia en un determinado mercado, mayores serán las posibilidades de que un intercambio entre competidores dé lugar a un resultado colusorio.

Por su parte, según el párrafo 78 de las Directrices horizontales, es la combinación del nivel preexistente de transparencia y del modo en que el intercambio de información modifica este nivel lo que determinará la probabilidad de que el intercambio tenga efectos restrictivos de la competencia.

En cuanto al carácter concentrado del mercado, es más probable que un intercambio facilite un resultado colusorio en oligopolios restringidos o en mercados en donde el número de empresas existentes es muy reducido.

Por último, también resultará más probable llegar a un resultado colusorio si las condiciones de la oferta y la demanda son relativamente estables ${ }^{36}$ y cuando el mercado presenta estructuras simétricas (cuando las empresas son homogéneas en términos de costes, demanda, cuotas de mercado, gama de productos, etc. $)^{37}$.

\subsubsection{Características de la información intercambiada}

Para determinar si un intercambio de información entre competidores es susceptible de tener efectos restrictivos de la competencia será relevante analizar las características de la información que se intercambia ${ }^{38}$. Las Directrices horizontales facilitan en los párrafos 86 a 94 una serie de parámetros a tener en cuenta a la hora de evaluar los efectos de la información intercambiada. Dichos parámetros se analizan de forma somera a continuación por su relevancia a la hora de servir como guía para la realización del análisis de la información intercambiada desde el punto de vista de la normativa de competencia.

Información estratégica. De acuerdo con el párrafo 86 de las Directrices horizontales, la información estratégica puede referirse a precios (incluyendo descuentos, aumentos, reducciones o rebajas), listas de clientes, costes de producción, cantidades, volúmenes de negocios, ventas, capacidades, calidades, planes de comercialización, riesgos, inversiones, tecnologías y programas de $\mathrm{I}+\mathrm{D}$ y sus resultados. Esta lista no es exhaustiva y en todo caso la utilidad de la información considerada estratégica dependerá también del análisis de los demás parámetros que incluyen las Directrices horizontales.

\footnotetext{
${ }^{36}$ Párrafo 81 de las Directrices horizontales.

${ }^{37}$ Párrafo 82 de las Directrices horizontales.

${ }^{38}$ Ver a este respecto Massaguer, J. y otros, Comentario a la Ley de Defensa de la Competencia, $3^{\mathrm{a}}$ ed., Civitas Thomson Reuters, Pamplona, 2012, pp. 66-67; y Recuerda, M. y otros, Problemas prácticos y actualidad del Derecho de la Competencia Anuario 2014, 1ª ed., Civitas Thomson Reuters, Pamplona, 2014, pp. 29-33.
} 
Cobertura del mercado. Para que un intercambio de información entre competidores tenga efectos sobre la competencia, habrá que analizar si el mismo cubre una parte suficientemente amplia del mercado en el que se produce el intercambio. En la práctica esto significa que será necesario determinar las cuotas de mercado de las partes del intercambio de información ${ }^{39}$.

Datos agregados/individualizados. Los intercambios de información agregada no suelen plantear problemas de competencia ${ }^{40}$ cuando no permiten reconocer la información individual de cada empresa ${ }^{41}$. De hecho, la recogida y publicación de datos de mercado agregados por una organización comercial o por una empresa de información sobre el mercado puede tener efectos positivos ${ }^{42}$. Por el contrario el intercambio de datos individualizados se considerará que dará lugar a una coordinación entre las partes ${ }^{43}$.

Antigüedad de los datos. Uno de los temas que más polémica suscita a la hora de evaluar un intercambio de información entre competidores es determinar con claridad cuando un dato puede considerarse o no histórico. En principio, según el párrafo 90 de las Directrices horizontales, no se ha definido un umbral a partir del cual los datos puedan considerarse históricos y, por lo tanto, suficientemente antiguos para no suponer un riesgo para la competencia. La consideración de los datos como históricos dependerá de las características específicas del mercado en cuestión y de la frecuencia de las renegociaciones de precios en el sector, así como del tipo de datos de que se trate, su agregación y la frecuencia del intercambio.

Frecuencia del intercambio de información. Según el párrafo 91 de las Directrices "los intercambios frecuentes de información que facilitan un mejor entendimiento común en el mercado como el control de las desviaciones aumentan los riesgos de resultado colusorio".

Datos públicos/no públicos. El intercambio de información verdaderamente pública entre competidores no constituirá normalmente una infracción de la nor-

${ }^{39}$ Posible aplicación de la Comunicación "de minimis" (Comunicación de la Comisión relativa a los acuerdos de menor importancia que no restringen la competencia de forma sensible en el sentido del artículo 101, apartado 1, del Tratado de Funcionamiento de la Unión Europea) en aquellos casos en los que el acuerdo en cuestión no tenga por lo general un alcance suficientemente amplio para dar lugar a efectos restrictivos de la competencia.

${ }^{40}$ Ver a este respecto Bellamy, C. y Child, G. D., European Community Law of Competition, $6^{\mathrm{a}}$ ed., Sweet \& Maxwell, Londres, 2014, pp. 358-359.

${ }^{41}$ Salvo en casos de oligopolios muy restringidos. En el primer caso de los cerveceros (Resolución de 30 de marzo de 2004 en el expediente A 329/02, Estadísticas cerveceros) la agregación de datos por vía notarial se consideró poco efectiva a efectos de enmascaramiento de datos individuales de cada partícipe ya que en varias zonas geográficas se producía un duopolio.

42 Párrafo 89 de las Directrices horizontales.

${ }^{43}$ Ver a este respecto Valdés, A., "La actividad de las empresas en el seno de las asociaciones empresariales a la luz de la jurisprudencia sobre defensa de la competencia”, Gaceta jurídica de la Unión Europea y de la Competencia, Ed. La Ley, (núm. 7, Enero-Febrero 2009). 
LOS INTERCAMBIOS DE INFORMACIÓN ENTRE COMPETIDORES DESDE EL PUNTO DE VISTA DEL DERECHO...

mativa de competencia ${ }^{44}$. De acuerdo con el párrafo 92 de las Directrices la información verdaderamente pública es "aquella a la que por lo general todos los competidores y clientes tienen acceso fácilmente (en términos de costes de acceso) [...] su obtención no debe ser más costosa para los compradores y las empresas no participantes en el sistema de intercambio que para las empresas que intercambian la información".

Intercambio público/no público de información. En general el hecho de intercambiar información en público puede disminuir la coordinación en el mercado siempre que las empresas no participantes en el intercambio, los competidores potenciales y los compradores estén en condiciones de limitar el posible efecto restrictivo de la competencia.

\subsection{Posible exención del artículo 1.3 de la LDC/101.3 del TFUE}

Para que pueda aplicarse la exención del artículo 1.3 de la LDC/101.3 del TFUE a un intercambio de información entre competidores es necesario que se cumplan cumulativamente las cuatro condiciones ahí establecidas: que el intercambio de información dé lugar a mejoras de la eficiencia, las restricciones a las que da lugar sean indispensables para generar las mejoras de eficiencia alegadas, se produzca un beneficio para los consumidores y por último no se elimine la competencia respecto de una parte sustancial de los productos de que se trate.

Este análisis debe realizarse caso por caso y según las características del tipo de información. Como ya se indicó anteriormente, un intercambio de información entre competidores no es una infracción de la normativa de defensa de la competencia "per se" y puede dar lugar a mejoras de la eficiencia ${ }^{45}$.

\section{LA PRÁCTICA DE LAS AUTORIDADES DE DEFENSA DE LA COMPETENCIA SOBRE INTERCAMBIOS DE INFORMACIÓN ENTRE COMPETIDORES}

Los intercambios de información entre competidores han sido objeto de análisis por parte de la Comisión Europea desde muy temprano ${ }^{46}$. En España, los primeros casos de intercambio de información entre competidores surgen a raíz de solicitudes de autorización de acuerdos individuales bajo la antigua Ley 16/1989, de 17

${ }^{44}$ Ver a este respecto Whish, R. y Bailey, D., Competition Law, $7^{\mathrm{a}}$ ed., Oxford University Press, Oxford, 2012, p. 545.

${ }^{45}$ Ver a este respecto Whish, R. y Bailey, D., Competition Law, $7^{\mathrm{a}}$ ed., Oxford University Press, Oxford, 2012, p. 546.

${ }^{46}$ Ver a este respecto Fernández, C., "Intercambios de Información”, en Martínez, S. y Petitbò, J. (dirs.), Los acuerdos horizontales entre empresas, Fundación Rafael del Pino-Marcial Pons, Madrid-Barcelona, 2009, pp. 191-212, donde se detallan todos los casos mencionados en esta parte del artículo. 
de julio, de Defensa de la Competencia, si bien no ha sido hasta la adopción de la nueva LDC cuando tanto la CNC como la CNMC han consolidado su práctica en numerosas resoluciones sobre intercambios de información entre competidores.

\subsection{Práctica de la Comisión Europea}

La primera referencia directa por parte de la Comisión Europea al análisis de los intercambios de información desde el punto de vista del Derecho de la Competencia tuvo lugar en la Comunicación de 1968 relativa a acuerdos de cooperación entre empresas ${ }^{47}$. La Comisión hacía hincapié en dicha Comunicación en que los intercambios de opiniones y experiencias entre competidores no debían restringir la libertad de las empresas para determinar su estrategia competitiva.

La Comisión Europea prohibió por primera vez un acuerdo de intercambio de información en 1974, en el asunto "Glass Containers"48, en el cual varios fabricantes de vidrio intercambiaron información sobre sus políticas de precios, tanto de manera directa como indirecta, en el marco de la asociación IFTRA. La Comisión calificó dicho intercambio como una práctica contraria al artículo 81 del TCE (actual artículo 101 del TFUE), por tratarse de información individualizada y entender que el único objetivo posible del intercambio era la coordinación entre competidores.

Más adelante, en el asunto "Cobelpa/VPN"49, la Comisión entendió que un acuerdo de intercambio de información entre los principales fabricantes holandeses y belgas de papel de impresión constituía una infracción del Derecho de la Competencia. La información intercambiada comprendía estadísticas y datos individualizados mensuales sobre precios y condiciones de venta. De acuerdo con el criterio de la Comisión, el intercambio de información estadística agregada no era contrario a las normas de competencia, a diferencia del intercambio de datos individualizados relativos a materias comercialmente sensibles. Estos intercambios contribuían, a juicio de la Comisión, a aumentar artificialmente la transparencia en el mercado y a reducir los riesgos competitivos ${ }^{50}$.

${ }^{47}$ Comunicación relativa a los acuerdos, decisiones y prácticas concertadas relativas a la cooperación entre empresas, de 29 de julio de 1968. Diario Oficial núm. C 075 de 29 de julio de 1968, pp. 3-6.

${ }^{48}$ Decisión de la Comisión 74/292/CEE, de 15 de mayo de 1974, en el asunto IV/400, Acuerdos entre fabricantes de vidrio para envases.

${ }^{49}$ Decisión de la Comisión 77/592/CEE, de 8 de septiembre de 1977, en el asunto IV/312-366, Cobelpa/VPN.

${ }^{50}$ De manera similar, en el asunto "Vegetable Parchment" (Decisión de la Comisión 78/252/CEE, de 23 de diciembre de 1977, en el asunto IV/29.176, Pergamino vegetal) se analizó un acuerdo entre los principales productores de pergamino vegetal en el marco de una asociación para el intercambio de información estadística y de datos individualizados sobre precios y exportaciones. La Comisión consideró en este caso que el intercambio de información individualizada creaba un sistema de solidaridad e influencia mutua que facilitaba la coordinación entre las empresas partícipes. La Comisión entendió que el intercambio podía considerarse restrictivo por su objeto, consistente en la modificación de las condiciones de competencia en el mercado. 
La Comisión analizó un acuerdo puro de intercambio de información entre competidores por primera vez en el asunto "UK Agricultural Tractor Registration Exchange" ${ }^{51}$, que tendría una gran influencia en la política aplicada por la Comisión a partir de entonces en relación con estos acuerdos. Se trataba de un acuerdo relativo al intercambio de información sobre volumen de ventas al por menor y cuotas de mercado administrado desde la asociación profesional de fabricantes e importadores de maquinaria agrícola del Reino Unido (AEA). En concreto, se intercambiaban tres tipos de información: (i) agregada sobre ventas industriales; (ii) sobre ventas y cuotas de mercado agregadas de cada fabricante individual; y (iii) relativa a las ventas hechas por los comerciantes en la red de distribución de cada miembro.

El acuerdo tenía lugar en un mercado con una alta concentración por el lado de la oferta, con cuatro grandes proveedores que conjuntamente controlaban más de tres cuartas partes del mercado y varios operadores de tamaño mucho menor. Esta situación se veía además agravada por el hecho de que en las zonas geográficas más pequeñas no estaban activos todos los proveedores, y porque no todos los proveedores ofrecían modelos de tractores de gran potencia. En consecuencia, para determinadas categorías de tractores existían sólo dos o tres proveedores activos en una zona geográfica concreta. Además, el mercado estaba caracterizado por la existencia de elevadas barreras de entrada, debido a que la comercialización de tractores requería una red de distribución densa y se trataba de un mercado en declive y con exceso de capacidad.

La Comisión valoró el acuerdo de intercambio de información considerando todas estas características del mercado. De esta forma, llegó a la conclusión de que el acuerdo suponía una infracción del artículo 81 del TCE (actual artículo 101 del TFUE), en tanto en cuanto suponía la eliminación de la incertidumbre del mercado a la vez que aumentaba los obstáculos de acceso al mercado para potenciales competidores. Se trata de la primera decisión de la Comisión que prohibió un sistema de intercambio de información entre competidores en el que los datos intercambiados no se referían a precios.

Por otro lado, a diferencia de los casos anteriores, la Comisión consideró que el acuerdo suponía una infracción de las normas de competencia por sus efectos, y no por su objeto. En el análisis la Comisión declaró que debían "tenerse en cuenta no sólo los efectos inmediatos y manifiestos de un acuerdo, sino también sus efectos posibles, así como la posibilidad de que un acuerdo cree una estructura que pueda ser utilizada para fines contrarios a la competencia" 52 .

\footnotetext{
${ }^{51}$ Decisión de la Comisión 92/57/CEE, de 17 de febrero de 1992, asunto UK Agricultural Tractor Registration Exchange. Ver a este respecto Bellamy, C. y Child, G. D., European Community Law of Competition, $6^{\mathrm{a}}$ ed., Sweet \& Maxwell, Londres, 2014, p. 356.

${ }^{52}$ La decisión fue recurrida ante los tribunales comunitarios y tanto el Tribunal de Primera Instancia (actual Tribunal General) como el TJCE confirmaron la decisión de la Comisión (Sentencia del Tribu-
} 
Con posterioridad al asunto "UK Agricultural Tractor Registration Exchange”, en 1993, el TJCE anuló parcialmente la decisión de la Comisión en el asunto "Ahlström Osakeyhtioe" 53 . En este caso operadores y asociaciones activos en el sector de la producción de pasta de madera comunicaban anticipadamente a clientes y agentes los precios que pretendían aplicar en cada trimestre. De acuerdo con la Comisión, esta práctica constituía una infracción del artículo 81 del TCE (actual artículo 101 del TFUE), en tanto en cuanto tenía como objetivo facilitar el conocimiento de los precios de otros competidores con suficiente antelación, lo cual aumentaba la transparencia en el mercado. La Comisión indicó además que este sistema de información suponía un indicio de la existencia de una concertación previa entre las empresas implicadas, puesto que se podía apreciar un paralelismo en la conducta de las mismas.

No obstante, el TJCE sostuvo que, atendiendo a las características del mercado, existían otras posibles justificaciones para dicho paralelismo. En este sentido, apuntó que el mercado de la pasta de madera estaba caracterizado por la existencia de relaciones a largo plazo entre los productores y sus clientes, por lo que ambas partes necesitaban reducir en la medida de lo posible sus riesgos comerciales. Además, el TJCE indicó también que se trataba de un mercado con un alto nivel de transparencia, independientemente de los acuerdos de intercambio de información que se estaban evaluando, y que mostraba tendencias oligopolísticas que podían explicar el paralelismo en la conducta de los distintos competidores.

Un año más tarde, en 1994, la Comisión analizó en el asunto "Cartonboard"54 un acuerdo de intercambio de información comercial estadística relativa a pedidos, capacidad y utilización de maquinaria establecido entre productores de cartoncillo que representaban una alta proporción del mercado. En este caso la Comisión sostuvo que el acuerdo de intercambio de información servía de base para el acuerdo colusorio dentro del cual estaba enmarcado. Esta decisión fue recurrida también ante el Tribunal de Primera Instancia, que confirmó que se trataba efectivamente de un intercambio de información ilegal porque contribuía a controlar el cumplimiento de un acuerdo restrictivo mayor. No obstante, el Tribunal anuló la prohibición impuesta por la Comisión en relación con el

nal de Primera Instancia de 27 de octubre de 1994, asunto T-35/92, John Deere/Comisión; y sentencia del TJCE de 28 de mayo de 1998, asunto C-7/95, John Deere/Comisión) señalando que en un mercado oligopolístico como el afectado por este acuerdo, los intercambios de información sensible producían una transparencia en el mercado que eliminaba la incertidumbre y potencialmente podían suponer una reducción de la competencia. No obstante, la doctrina ha criticado esta postura de los tribunales, alegando que se podía interpretar como una prohibición "per se" de los intercambios de información en mercados oligopolísticos.

${ }^{53}$ Sentencia del TJCE de 31 de marzo de 1993, asuntos acumulados C-89/85, C-104/85, C-114/85, C-116/85, C-117/85 y C-125 a 129/85, Ahlström Osakeyhtioe y otros c. Comisión.

${ }^{54}$ Decisión de la Comisión 94/601/CE, de 13 de julio de 1994, asunto IV/C/33.833, Cartonboard. 
intercambio de información estadística global, ya que incluía tanto intercambios lícitos como ilícitos ${ }^{55}$.

Por último, merece la pena también citar, no en relación con la práctica de la Comisión Europea pero sí con la de los tribunales comunitarios, la sentencia del TJCE en el asunto Asnef-Equifax ${ }^{56}$, como ejemplo de caso en el que se ha realizado un análisis de eficiencias ${ }^{57}$. La sentencia se dictó en el marco de una cuestión prejudicial planteada por el Tribunal Supremo español, que estaba analizando un intercambio de información entre competidores que servía para la elaboración de un registro de solvencia. El TJCE reconoció que podían derivarse efectos positivos para los consumidores y la economía en general, en tanto en cuanto este intercambio contribuía a aumentar la información de que disponían las entidades de crédito acerca de los potenciales prestatarios y, en consecuencia, reducía la asimetría de información disponible para el acreedor y el deudor. En este caso, se consideró que la reducción de la incertidumbre de las entidades crediticias respecto a la situación financiera de los prestatarios mejoraba la eficiencia interna de dichas entidades y contribuía a mejorar la oferta de crédito en el mercado.

\subsection{Práctica inicial de las autoridades españolas de defensa de la competen- cia: asuntos más relevantes del TDC}

En España, los primeros asuntos de intercambio de información fueron analizados a partir de solicitudes de autorización de acuerdos individuales ${ }^{58}$. Así, en el año 2002, el TDC declaró, en el asunto "Información estadística FENIL" 59 , que un acuerdo de la Federación Nacional de Industrias Lácteas (FENIL) por el que se pretendía realizar un plan de recogida de datos agregados relativo a los precios y a los volúmenes de leche comercializados por las Comunidades Autónomas no constituía un acuerdo restrictivo de la competencia que fuera necesario autorizar.

Dos años después, el TDC adoptó la resolución en el asunto "Estadísticas cerveceros" que fue la primera gran resolución sobre los criterios aplicables a los

\footnotetext{
55 También procede referirse al asunto "Plasterboard" (Decisión de la Comisión 2005/471/CE, de 27 de noviembre de 2002, asunto COMP/E.1/37.152, Paneles de yeso), en el cual el intercambio de información quedaba enmarcado dentro de un cártel. No obstante, la Comisión sostuvo que cuando un intercambio de información conlleva que los competidores dejen de actuar de manera independiente en el mercado debe calificarse como una infracción "per se" del artículo 81 del TCE (actual artículo 101 del TFUE).

${ }^{56}$ Sentencia del TJCE de 23 de noviembre de 2006, asunto C-238/05, Asnef-Equifax.

${ }^{57}$ Ver a este respecto Whish, R. y Bailey, D., Competition Law, $7^{\mathrm{a}}$ ed., Oxford University Press, Oxford, 2012, pp. 544-545.

${ }^{58}$ Ver a este respecto Fernández, C., "Intercambios de Información”, en Martínez, S. y Petitbò, J. (dirs.), Los acuerdos horizontales entre empresas, Fundación Rafael del Pino-Marcial Pons, Madrid-Barcelona, 2009, pp.191-212.

${ }^{59}$ Resolución de 1 de marzo de 2002 en el expediente A 309/01, Información Estadísticas Fenil.
} 
intercambios de información y que se originó a raíz de la solicitud de autorización de un acuerdo de intercambio de información por la Asociación de Cerveceros de España (ACE) para un sistema de recopilación de datos estadísticos referente a la fabricación y comercialización de cerveza. El TDC consideró que el acuerdo suponía un incremento del riesgo de colusión entre las empresas y denegó la autorización singular, entre otras razones, debido a que la información intercambiada constituía secreto de negocios de las empresas y a que el mercado se encontraba muy concentrado ${ }^{60}$.

Otra importante resolución, esta vez ya fuera del contexto de solicitudes de autorización singulares, fue la adoptada por el TDC en el asunto "Distribuidores de cine" ${ }^{61}$ por la que se sancionó a la Federación de Distribuidores de Cinematográficos (FEDICINE) con 900.000 euros por una infracción del artículo 1 de la LDC por haber creado una base de datos por la que las empresas distribuidoras intercambiaban datos estratégicos sensibles, tales como fecha para los estrenos, cifras desagregadas de facturación, semanas de exhibición y salas y cuyo objeto, según el TDC, no era otro que el de restringir la competencia ${ }^{62}$.

\subsection{Práctica reciente de la $\mathrm{CNC}$ y de la CNMC}

En los últimos años tanto la CNC como la CNMC han adoptado numerosas resoluciones en donde han sancionado determinados intercambios de información entre competidores como una infracción de la normativa de defensa de la competencia $^{63}$. En ellas, es habitual que la CNMC acabe concluyendo que el intercambio de información entre competidores, habida cuenta de las características de los mercados en los que han tenido lugar y sobre todo de los datos intercambiados, constituye una infracción "por objeto" de la normativa de defensa de la competencia y no considere necesario analizar en detalle los posibles efectos restrictivos sobre la competencia.

El intercambio de información entre competidores sobre precios (actuales y futuros) y sus distintas variables es sin duda alguna el intercambio más investiga-

\footnotetext{
${ }^{60}$ Resolución de 30 de marzo de 2004 en el expediente A 329/02, Estadísticas cerveceros. Posteriormente, mediante Resolución de 11 de julio de 2007 el TDC autorizó durante cinco años el sistema de intercambio de información revisado supeditado al cumplimiento de varias condiciones (Resolución en el expediente A 360/06, Estadísticas cerveceros 2). Ver a este respecto Massaguer, J. y otros, Comentario a la Ley de Defensa de la Competencia, $3^{\mathrm{a}}$ ed., Civitas Thomson Reuters, Pamplona, 2012, p. 67.

${ }^{61}$ Resolución de 10 de mayo de 2006 en el expediente 588/05.

${ }^{62}$ Ver a este respecto Massaguer, J. y otros, Comentario a la Ley de Defensa de la Competencia, $3^{\mathrm{a}}$ ed., Civitas Thomson Reuters, Pamplona, 2012, pp. 65-66.

${ }^{63}$ Como ya se ha indicado en la introducción de este artículo, los intercambios de información entre competidores se han investigado y sancionado tanto como un intercambio de información puro o como parte de una infracción más compleja, donde el intercambio es la práctica fundamental o simplemente una de las ramas más de la infracción.
} 
do y sancionado por las autoridades españolas de defensa de la competencia en los últimos y más recientes asuntos en la materia, si bien también se han investigado y sancionado casos donde el dato intercambiado no era el precio o sus variables sino, por ejemplo, los datos relativos a cantidades como unidades producidas o número de transacciones comerciales realizadas. En cualquier caso, la conclusión a la que llega la autoridad de competencia es casi siempre la misma: el intercambio constituye una infracción "por objeto" y, en algunos casos, hasta un cártel.

\subsubsection{Infracción "por objeto": algunas resoluciones sobre intercambios de información} entre competidores sobre precios actuales ofuturos considerados estratégicos

Son numerosos los casos en los que la CNC o la CNMC han investigado y sancionado intercambios de información cuyo principal dato intercambiado era el precio, tanto actual como futuro, y sus distintas variables. Los casos analizados a continuación son, en opinión de los autores, los casos en los cuales queda patente de manera más clara cuál es la postura de la $\mathrm{CNC}$ o la $\mathrm{CNMC}$ al respecto del intercambio de información entre competidores de precios actuales o futuros y la problemática de su calificación como infracción "por objeto" constituyendo, además, una buena guía de análisis a la hora de tratar este tipo de intercambios de información.

El primer gran caso relevante es el asunto "STANPA", cuya resolución fue adoptada el siete de febrero de 2011 por la CNC, en donde la conducta analizada consistía en intercambios de información de tarifas de precios, así como también de determinada información estadística, en el seno de varios comités de la Asociación Nacional de Perfumería y Cosmética (STANPA) entre enero de 2004 y mayo de $2008^{64}$.

La Resolución se refiere a la doctrina y precedentes aplicables a los intercambios de información entre competidores en sus Fundamentos de Derecho Cuarto, Quinto y Sexto (página 43 en adelante) en lo que parecía un intento claro de la CNC por analizar estas cuestiones y sentar un precedente relevante en la materia (citando además a las, en ese momento, recién adoptadas Directrices horizontales que incluían por primera vez un apartado específico sobre los intercambios de información).

De hecho, la CNC hace referencia expresa a los apartados 72 y 74 de las nuevas Directrices horizontales relativos a los intercambios de información "por objeto". Para la Resolución, el intercambio de tarifas de precios sancionado era

\footnotetext{
${ }^{64}$ Resolución de 7 de febrero de 2011 en el asunto S/0155/09, STANPA por el que la CNC sancionó a STANPA con una multa de 901.518 euros por una infracción del artículo 1 de la LDC consistente en un intercambio de información desde el 26 de enero de 2004 hasta el 8 de mayo de 2008. La multa impuesta a STANPA fue reducida posteriormente a raíz de la estimación parcial de su recurso ante la Audiencia Nacional (que confirmó los demás extremos de la Resolución de la CNC).
} 
uno de los más dañinos puesto que se intercambian "precios actuales y futuros de una serie muy desagregada de los correspondientes productos". En este sentido, la CNC negaba que se tratasen de precios pasados como alegaba STANPA pues "se trataba de precios actuales y previstos para el futuro" que incluían también "la notificación con antelación de cualquier variación o modificación de las tarifas". En base a ello, para la CNC los intercambios de información de precios que proporcionan información con una exhaustividad tal que permiten a las empresas conocer las actuaciones y las tendencias concretas de otras empresas anulan o reducen gravemente la incertidumbre estratégica, la independencia en las políticas comerciales y el incentivo para competir de las empresas ${ }^{65}$. En definitiva, para la CNC estos intercambios por su propia naturaleza constituían una infracción "por objeto", siendo anticompetitivo "sin más demostración".

En la Resolución adoptada muy poco después (el dos de marzo de 2011) en el asunto relacionado "Peluquería profesional" 66 , la CNC sancionó a varias empresas y a STANPA por su participación en un cártel instrumentalizado a través de un sistema de intercambio de información de precios actuales y futuros ${ }^{67}$ haciendo de nuevo mención expresa a los apartados 72 y 74 de las Directrices horizontales relativos a los intercambios de información "por objeto". Para la CNC fue evidente que el intercambio de información sobre los precios constituía una infracción "por objeto" y, más aún, consideró que el intercambio de información podía ser calificado como cártel en el sentido de la Disposición Adicional Cuarta de la LDC, "por cuanto se limitaba a intercambios ente las ocho empresas que formaban el cártel y porque tenían por objeto una restricción de la competencia en precios, cantidades y otras variables competitivas equivalente a una fijación de precios" ${ }^{68}$.

En el caso "Bombas de fluidos" 69 , la CNC sancionó, entre otras conductas, los intercambios de información entre varias empresas del sector relativos a incrementos de precios futuros y sus fechas de entrada en vigor, previsiones de produc-

${ }^{65}$ Página 49 de la Resolución.

${ }^{66}$ Resolución de la CNC de dos de marzo de 2011 en el asunto S/0086/08, Peluquería profesional por el que se impuso varias multas por un valor total de aproximadamente 51 millones de euros a determinadas empresas del sector de los productos de peluquería profesional (a la empresa Henkel se le eximió de la multa en aplicación del programa de clemencia). La multa a otra de las empresas sancionadas, Wella, fue anulada por la Audiencia Nacional (posteriormente la CNC calculó una nueva multa para Wella en aplicación del programa de clemencia). En cuanto a STANPA, la multa que le fue impuesta fue reducida a raíz de la estimación parcial de su recurso ante la Audiencia Nacional, quien confirmó los demás extremos de la Resolución.

${ }^{67}$ Ver a este respecto Massaguer, J. y otros, Comentario a la Ley de Defensa de la Competencia, $3^{\mathrm{a}}$ ed., Civitas Thomson Reuters, Pamplona, 2012, p. 68.

${ }^{68}$ Página 99 de la Resolución, tercer párrafo.

${ }^{69}$ Resolución de 24 de junio de 2011 en el expediente S/0185/09, Bombas de fluidos. La Resolución fue recurrida ante la Audiencia Nacional por varias de las empresas si bien todos los recursos han sido desestimados a excepción del recurso interpuesto por Wilo Ibérica, S. A. que ha sido estimado parcialmente reduciéndose la multa que le había sido impuesta a dicha sociedad. 
ción y demanda, políticas salariales y cifras de facturación. Para la CNC, dichos intercambios debían calificarse como acuerdos de cártel ${ }^{70}$ puesto que obedecían a la pretensión de las empresas de reducir la incertidumbre en el mercado conociendo mejor la estrategia comercial del resto de empresas lo que repercutía en el refuerzo de su poder negociador frente a clientes ${ }^{71}$.

Para la CNC los intercambios eran susceptibles de reducir la competencia en precios al tratarse de información no observada todavía (en concreto incrementos de precios futuros) o no observables con facilidad, mencionando expresamente el apartado 72 de las Directrices horizontales relativo a la restricción de la competencia "por objeto" 72 .

En el caso más reciente de "Industrias lácteas 2"73, la CNMC consideró que el intercambio de información de precios era una infracción "por objeto" e indicó por lo que respecta a la información intercambiada que "es indudable, a raíz de cuanto se ha señalado, que el tipo de información aquí intercambiada, particularmente sobre precios, ganaderos (incluye identidad de los ganaderos y volúmenes de compra de leche a los mismos) y excedentes de leche debe ser considerada información estratégica de las empresas"74.

Según la Resolución, además de considerar el intercambio como una infracción "per se" de la normativa de competencia, concurrían en este caso tres elementos adicionales que agravaban la antijuridicidad de las conductas: el carácter desagregado de la información intercambiada, la frecuencia y continuidad de los contactos entre las empresas y la actualidad de la información, dado que se trataba de precios recientes y precios futuros que se pretendían aplicar a los ganaderos ${ }^{75}$.

Merece la pena destacar que la CNC ha calificado también como infracción "por objeto" un intercambio de información entre competidores sobre precios actuales pero no futuros (asunto Suzuki-Honda ${ }^{76}$ ). Para la CNC el intercambio de correos electrónicos entre Suzuki y Honda del día 21 de enero de 2009 encajaba en el concepto de práctica concertada restrictiva de la competencia "por objeto" y por tanto prohibida por el artículo 1 de la LDC. "Se trata de un contacto directo

\footnotetext{
${ }^{70}$ Página 90 de la Resolución.

${ }^{71}$ Página 103 de la Resolución.

${ }^{72}$ Página 108 de la Resolución.

${ }^{73}$ Resolución de 26 de febrero de 2015 en el expediente S/0425/12, Industrias lácteas 2. Al momento de escribir este artículo, la página web de la CNMC no ha indicado si la Resolución ha sido recurrida todavía.

${ }^{74}$ Página 61 de la Resolución.

${ }^{75}$ Página 62 de la Resolución.

${ }^{76}$ Resolución de 19 de enero de 2012 en el expediente S/0280/10, Suzuki-Honda, donde la CNC sancionó a Montesa Honda con 2.098.280 euros y a Suzuki con 1.881.570 euros por una infracción del artículo 1 de la LDC. La Resolución de la CNMC ha sido recurrida ante la Audiencia Nacional si bien todavía no se ha adoptado ninguna sentencia.
} 
entre competidores reales en el mercado considerado, en el que las empresas imputadas, a través del correo electrónico de sus directivos, intercambian datos individualizados relativos a sus precios mayoristas y minoristas vigentes en principio para todo el año 2009 de distintos tipos de modelos de motocicletas [...]".

Y pese a que se trataba de un único intercambio de información, la CNC consideró que debido a la naturaleza de la información intercambiada y el contexto temporal, ese intercambio de información era objetivamente apto para reducir la incertidumbre estratégica del mercado.

Por último, en la resolución más reciente publicada en la página web de la CNMC al momento de escribir este artículo, la Resolución de 18 de junio de 2015 en el asunto "Fabricantes de papel y cartón ondulado", la CNMC ha considerado, en lo que podría interpretarse como un posible nuevo enfoque en la materia, que el intercambio de información sobre el precio de fabricación de papel para el cartón ondulado no podía considerarse como una infracción "por objeto" al no tratarse de precios futuros sino simplemente pasados.

\subsubsection{Infracciones "por objeto": algunas resoluciones sobre intercambios de informa-} ción entre competidores de datos pasados no relativos a precios

La CNMC también ha investigado casos de intercambios de información de datos no relativos a precios, sino a otros parámetros considerados como estratégicos por la CNMC a la hora de competir. Los casos recientes más relevantes son sin duda alguna los relativos a "Servicios comerciales AENA" y "Palés" ya que en ambos se trataba de información histórica (es decir no actual y menos aún futura) principalmente sobre cantidades.

En el caso "Servicios comerciales AENA"77, la conducta investigada se refería a la circulación de determinada información contenida en unos informes realizados por AENA entre las empresas de servicios de alquiler de coches de prácticamente todos los aeropuertos de España de forma constante en el tiempo y, en algunos casos, con una duración de hasta 18 años.

La información contenida en los informes de AENA era información muy general sobre volumen de negocios y el número de operaciones realizadas por las empresas de servicios de alquiler de coches en cada uno de los aeropuertos. En todo caso, es importante destacar que la información circulada por AENA no contenía referencia alguna a los elementos fundamentales de carácter comercial alegados por las empresas durante el procedimiento administrativo, como, por ejemplo, la duración de los contratos, la clase de vehículo alquilado o los extras adicionales incluidos en cada contrato.

\footnotetext{
${ }^{77}$ Resolución de la CNMC de 2 de enero de 2014 en el expediente S/0404/12, Servicios comerciales AENA. La Resolución de la CNMC ha sido recurrida ante la Audiencia Nacional por varias de las empresas sancionadas si bien todavía no se ha adoptado ninguna sentencia.
} 
La CNMC sancionó a un total de 17 empresas, así como a AENA, con casi cinco millones de euros en multas por un intercambio de información comercialmente sensible entre competidores y en su Resolución consideró que la conducta del intercambio de información debería haberse subsumido en otra conducta de cártel investigada por la CNMC en otro expediente (S/0380/11, Coches de alquiler) que ya había sido sancionado anteriormente. La Resolución no contiene un análisis detallado ni de las características del mercado ni tampoco del tipo de información intercambiada y se limita a indicar que "al margen del tipo y naturaleza de la información intercambiada entre las empresas imputadas, la elevada frecuencia (mensual) de los intercambios y la escasa antigüedad de los datos (a mes vencido) se corrobora el predominio de las empresas de alquiler de coches con mayor cuota en el mercado de alquiler de coches"78.

La Resolución también considera que los intercambios investigados no solo tenían aptitud para reducir la independencia de las empresas a la hora de tomar decisiones sino que también permitió a las empresas debilitar o suprimir el grado de incertidumbre en el mercado dando lugar a un resultado colusorio ${ }^{79}$. En este sentido, y aunque no indica expresamente que se trata de una infracción "por objeto", cabe deducir de lo anterior que esa era la interpretación de la CNMC ${ }^{80}$.

En el caso de los "Palés" 1 , la Resolución de la CNMC consideró que determinadas empresas competidoras habían participado en una infracción de la normativa de competencia consistente en un intercambio de información sobre cifras de producción de palés de madera calidad controlada EUR/EPAL desde enero de 2005 hasta noviembre de 2011 (además en la Resolución también se sancionó a varias empresas por un cártel de fijación de precios en el mercado de los palés, considerando la CNMC que ambas conductas constituyeron una infracción única y continuada si bien sancionó a las distintas empresas de manera individual por su participación o en el intercambio, o en el cártel, o en algunos casos en ambos).

El intercambio de información sancionado habría tenido lugar, según el relato de la Resolución, a través del envío trimestral por parte de la asociación del sector CALIPAL de unos informes con cifras mensuales de producción de palés de madera calidad controlada EUR/EPAL entre enero de 2005 y octubre de 2008, así como a través de los informes anuales repartidos en las Asambleas Generales de CALIPAL hasta noviembre de 2011.

\footnotetext{
${ }^{78}$ Página 11 de la Resolución.

${ }^{79}$ Páginas 10 y 11 de la Resolución.

${ }^{80}$ Interpretación reforzada por el hecho de que en la Resolución no se contiene un análisis de los posibles efectos concretos del intercambio de información sancionado en el mercado.

${ }^{81}$ Resolución de 2 de septiembre de 2014 en el expediente S/0428/12, Palés. La Resolución de la CNMC ha sido recurrida ante la Audiencia Nacional por varias de las empresas sancionadas si bien todavía no se ha adoptado ninguna sentencia.
} 
La información no era por lo tanto actual ni futura sino relativa a, al menos, varios meses (en el caso de los informes trimestrales) e incluso a año vencido (en el caso de los informes anuales), sobre cifras de producción de palés. Para la CNMC "el intercambio de información aqui analizado encaja, por tanto, en la categoría de información estratégica, ya que se refiere a datos de producción y/o reparación de palés de las empresas competidoras, de la que se puede deducir, por ejemplo, las cantidades producidas y reparadas, los volúmenes de negocio y capacidades de las empresas, así como cuotas de mercado" 82 . De lo anterior se deduce que para la CNMC el dato intercambiado, unidades de producción de palés, era un dato estratégico pese a no referirse a datos futuros de los competidores.

Para la Resolución "resulta evidente" que las conductas tuvieron no solo aptitud sino que produjeron efectos en el mercado puesto que aumentaron la transparencia en el mismo, lo que facilitó la coordinación del comportamiento competitivo de las empresas e incrementó la estabilidad interna del mercado. Sin embargo, pese a todo ello, la Resolución no contiene una identificación concreta de cuales han podido ser dichos efectos en el mercado, es decir, de cómo se facilitó la coordinación del comportamiento de los competidores o cómo se disminuyó el coste del desarrollo de la conducta y los incentivos para competir.

La Resolución tampoco contiene un análisis pormenorizado ni del mercado ni de las características de los datos intercambiados. La Resolución tan solo indica a estos efectos que "en atención a la periodicidad del intercambio y del propio contenido de los datos intercambiados relativos a la cifras desagregadas y mensuales de producción, se ha de concluir que esos intercambios tenían aptitud para restringir la competencia, teniendo en cuenta, además, las características del mercado en que se produjeron, por cuanto las empresas ostentan prácticamente el 100\% de la cuota de mercado" 83 .

\section{CONCLUSIONES}

Los intercambios de información entre competidores no son una conducta per se contraria a la normativa de defensa de la competencia. Al contrario existen intercambios que generan eficiencias y son por lo tanto pro-competitivos.

Para saber distinguir cuando un intercambio de información entre competidores puede constituir una infracción o cuando es pro-competitivo es necesario autoevaluar el intercambio teniendo en cuenta (i) la estructura del mercado afectado; (ii) las características de la información intercambiada; y (iii) el modo en que se producen los intercambios de información.

\footnotetext{
82 Página 112 de la Resolución, segundo párrafo.

${ }^{83}$ Página 118 de la Resolución, último párrafo.
} 
La ausencia de regulación legal específica sobre los intercambios de información entre competidores ha puesto en valor la práctica decisoria de las autoridades de competencia, de los tribunales y sobre todo de las Directrices horizontales que facilitan una importante guía para la autoevaluación de los acuerdos.

La práctica reciente de la CNMC pone de manifiesto que los intercambios de información entre competidores investigados y sancionados han sido calificados casi siempre de infracción de la normativa de defensa de la competencia "por objeto", aun en casos en los cuales la información intercambiada entre competidores difícilmente podría considerarse relativa a precios o cantidades futuras.

Esta calificación supone que la CNMC no tenga que probar los eventuales efectos del intercambio en el mercado cuando, de hacerlo, pudiera ser probable la constatación de la ausencia de efectos sobre la competencia derivados del intercambio de información sobre datos de precios y cantidades históricos.

Resulta cuestionable para los autores de este artículo que aquellos casos en los cuales el intercambio de información entre competidores no se refiera expresamente a datos sobre precios y cantidades futuras puedan ser calificados como una infracción "por objeto" por la CNMC. De hecho, de las propias Directrices horizontales (que no hacen sino plasmar la jurisprudencia más relevante en la materia) se desprende con claridad que solo serán infracciones "por objeto" aquellos intercambios de información entre competidores que forman parte de un cártel como tal o aquellos intercambios de información que permitan deducir acciones futuras, mientras que aquellos otros intercambios que no permitan de manera alguna deducir acciones futuras solo podrían ser una infracción "por objeto" bajo determinadas circunstancias que deberán ser, en todo caso, analizadas de manera pormenorizada por las autoridades.

Sin embargo, en la práctica vemos que la CNMC ha calificado de infracción "por objeto" intercambios de información que no encajarían en lo indicado por las Directrices horizontales, haciendo una interpretación muy amplia del concepto "por objeto" cuando resulta claro de las Directrices y de la jurisprudencia comunitaria más reciente que dicha interpretación debe ser restrictiva. Como consecuencia, la CNMC ha sancionado a muchas empresas sin, en opinión de los autores, suficiente motivo creando inseguridad jurídica lo que podría ser un obstáculo para fomentar los intercambios de información que sí tienen naturaleza pro-competitiva.

Con la reciente publicación de la Resolución de 18 de junio de 2015 en el asunto "Fabricantes de papel y cartón ondulado", la CNMC sí ha considerado de manera acertada y en línea con las Directrices horizontales y la jurisprudencia que el intercambio de información entre competidores sobre el precio de fabricación de papel para el cartón ondulado no podía considerarse como una infracción "por objeto" al no tratarse de precios futuros sino pasados. Creemos que éste debería ser el enfoque predominante de la CNMC a partir de ahora en casos similares. 
Por otro lado, muchos de los asuntos sancionados por la CNC o la CNMC relativos a intercambios de información entre competidores han sido recurridos ante la jurisdicción contencioso-administrativa y sería deseable que en las sentencias que resuelvan dichos recursos la Audiencia Nacional o el Tribunal Supremo aclaren su interpretación al respecto de la calificación de este tipo de acuerdos.

\section{BIBLIOGRAFÍA}

BELLAMY, C. y CHILD, G. D., European Community Law of Competition, $6^{\mathrm{a}}$ ed., Sweet \& Maxwell, Londres, 2014.

FERNÁNDEZ, C., "Intercambios de Información”, en Martínez, S. y Petitbò, J. (dirs.), Los acuerdos horizontales entre empresas, Fundación Rafael del Pino-Marcial Pons, Madrid-Barcelona, 2009, pp.191-212.

GONZÁLEZ-PÁRAMO, C. y GÓMEZ, A., "Las actividades de las asociaciones sectoriales y el Derecho de la competencia: ¿bajo permanente sospecha?", Diario La Ley, Ed. La Ley, (núm. 8401, Octubre 2014).

JONES, A. y SUFRIN, B., EU Competition Law, $5^{\mathrm{a}}$ ed., Oxford University Press, Oxford, 2014.

LORCA, T., "El intercambio de información en las asociaciones empresariales: hasta dónde es posible llegar sin incurrir en una infracción del derecho de la competencia", Gaceta jurídica de la Unión Europea y de la Competencia, Ed. La Ley, (núm. 18, Noviembre-Diciembre 2010).

MASSAGUER, J. y otros, Comentario a la Ley de Defensa de la Competencia, $3^{\mathrm{a}}$ ed., Civitas Thomson Reuters, Pamplona, 2012.

ORTIZ, L. y otros, Manual de Derecho de la Competencia, $1^{\mathrm{a}}$ ed., Tecnos, Madrid, 2008.

RECUERDA, M. y otros, Problemas prácticos y actualidad del derecho de la competencia Anuario 2014, 1ª ed., Civitas Thomson Reuters, Pamplona, 2014.

VALDÉS, A., "La actividad de las empresas en el seno de las asociaciones empresariales a la luz de la jurisprudencia sobre defensa de la competencia", Gaceta jurídica de la Unión Europea y de la Competencia, Ed. La Ley, (núm. 7, Enero-Febrero 2009).

VALDÉS, A. y FAURA, P., "Intercambios ilícitos de información entre competidores: límites y conexión con los cárteles y la clemencia”, Gaceta jurídica de la Unión Europea y de la Competencia, Ed. La Ley, (núm. 32, Sección Artículos, Marzo-Abril 2013).

VELASCO, L. y otros, Acuerdos horizontales, mercados electrónicos y otras cuestiones actuales de competencia y distribución, $1^{\mathrm{a}}$ ed., Lex Nova Thomson Reuters, Valladolid, 2014. 
LOS INTERCAMBIOS DE INFORMACIÓN ENTRE COMPETIDORES DESDE EL PUNTO DE VISTA DEL DERECHO...

WHISH, R. y BAILEY, D., Competition Law, $7^{\text {a }}$ ed., Oxford University Press, Oxford, 2012.

\section{JURISPRUDENCIA}

\section{Resoluciones CNMC:}

Resolución del TDC de 1 de marzo de 2002 en el expediente A/309/02, Informaciones Estadísticas Fenil.

Resolución del TDC de 30 de marzo de 2004 en el expediente A/329/02, Estadísticas Cerveceras.

Resolución del TDC de 10 de mayo de 2006 en el expediente 588/05, Distribuidores de Cine.

Resolución del TDC de 11 de julio de 2007 en el expediente A/360/06, Estadísticas Cerveceras 2.

Resolución de la CNC de 7 de febrero de 2011 en el expediente S/0155/09, STANPA.

Resolución de la CNC de 2 de marzo de 2011 en el expediente S/0086/08, Peluquería Profesional.

Resolución de la CNC de 24 de junio de 2011 en el expediente S/0185/09, Bombas de Fluidos.

Resolución de la CNC de 19 de enero de 2012 en el expediente S/0280/10, Suzuki-Honda.

Resolución de la CNMC de 30 de julio de 2013 en el expediente S/0380/11, Coches de Alquiler.

Resolución de la CNMC de 2 de enero de 2014 en el expediente S/0404/12, Servicios Comerciales AENA.

Resolución de la CNMC de 22 de septiembre de 2014 en el expediente S/0428/12, Pales.

Resolución de la CNMC de 25 de febrero de 2015 en el expediente S/0474/13, Precios Combustibles Automoción.

Resolución de la CNMC de 26 de febrero de 2015 en el expediente S/0425/12, Industrias Lácteas 2.

Resolución de la CNMC de 18 de junio de 2015 en el expediente S/0469/13, Fabricantes de Papel y Cartón Ondulado.

\section{Sentencias tribunales españoles:}

Sentencia Audiencia Nacional, Sala Contencioso-Administrativo, Sección $6^{\text {a }}$ de 1 de diciembre de 2009 (491/2007), Cajas Vascas. 


\section{Decisiones de la Comisión Europea:}

Decisión de la Comisión Europea de 17 de diciembre de 1992 en el asunto IV/31.370 y 31.446, UK Agricultural Tractor Registration Exchange.

Decisión de la Comisión 94/601/CE de 13 de julio de 1994 en el asunto IV/C/33.833, Cartonboard.

Decisión de la Comisión de 26 de noviembre de 1997 en el asunto IV/36.069, Wirtschaftsvereinigung Stahl.

Decisión de la Comisión 94/601/CE de 27 de noviembre de 2002 en el asunto COMP/E.1/37.152, Paneles de Yeso.

\section{Sentencias tribunales comunitarios:}

Sentencia del TJCE de 31 de marzo de 1993 en los asuntos acumulados C-89/85, C-104/85, C-114/85, C-116/85, C- $117 / 85$ y C-125 a 129/85, Ahlström Osakeyhtioe and others / Commission.

Sentencia del TGUE de 21 de noviembre de 1994 en el asunto T-35/92, John Deere / Commission.

Sentencia del TJUE de 28 de mayo de 1998 en el asunto C-7/95, John Deere / Commission.

Sentencia del TJCE de 23 de noviembre de 2006 en el asunto C-238/05, Asnef-Equifax/ Ausbanc/ Commission.

Sentencia del TJUE de 4 de junio de 2009 en el asunto C-8/08, T-mobile Netherlands and others / Commission.

Sentencia del TJUE de 6 de octubre de 2009 en el asunto C-501/06 P, Glaxo Smith Klim Services and others / Commission.

Sentencia del TJUE de 20 de noviembre de 2009 en el asunto C-209/07, Beef Industry Development and Barry Brothers / Commission.

Sentencia del TJUE de 6 de septiembre de 2014 en el asunto C-67/13 P, Groupment des Cartes Bancaires. 